\title{
Effects of Parental Public Health Insurance Eligibility on Parent and Child Health Outcomes
}

\author{
Maithreyi Gopalan, Ph.D. ${ }^{*}$ \\ Caitlin McPherran Lombardi, Ph.D. ${ }^{2 *}$ \\ Lindsey Rose Bullinger, Ph. $\mathrm{D}^{3^{*}}$
}

Affiliations: ${ }^{1}$ The Pennsylvania State University, ${ }^{2}$ University of Connecticut, ${ }^{3}$ Georgia Institute of Technology; *Contributed equally as co-first authors

Address correspondence to: Maithreyi Gopalan, Department of Education Policy Studies, The Pennsylvania State University, 302B Rackley Building, University Park, PA 16801, 734-6044393, smg632@psu.edu

Short title: Impact of Parental Public Health Insurance on Health

Conflict of Interest Disclosures: The authors have no conflicts of interest relevant to this article to disclose.

Funding/Support: We acknowledge the restricted-use data access and a seed grant provided by the Population Research Institute at Penn State University, which is supported by an infrastructure grant by the Eunice Kennedy Shriver National Institute of Child Health and Human Development (P2CHD041025), to Gopalan.

Role of Funder/Sponsor (if any): Our funders had no role in the design and conduct of the study.

Abstract: Many states expanded their Medicaid programs to low-income adults under the Affordable Care Act (ACA). These expansions increased Medicaid coverage among low-income parents and their children. Whether these improvements in coverage and healthcare use lead to better health outcomes for parents and their children remains unanswered. We used longitudinal data on a large, nationally representative cohort of elementary-aged children from low-income households from 2010-2016. Using a difference-in-differences approach in state Medicaid policy decisions, we estimated the effect of the ACA Medicaid expansions on parent and child health. We found that parents' self-reported health status improved significantly post-expansion in states that expanded Medicaid through the ACA by 4 percentage points $(p<0.05)$, a $4.7 \%$ improvement. We found no significant changes in children's use of routine doctor visits or parents' assessment of their children's health status. We observed modest decreases in children's body mass index (BMI) of about $2 \%(\mathrm{p}<0.05)$, especially for girls.

\section{Contributors' statements}

Dr. Gopalan conceptualized and designed the study, carried out the data analyses, drafted the initial manuscript, and reviewed and revised the manuscript.

Dr. Lombardi conceptualized and designed the study, provided feedback on data analyses, and reviewed and revised the manuscript. 
46 Dr. Bullinger conceptualized and designed the study, provided feedback on data analyses,

47 drafted the initial manuscript, and reviewed and revised the manuscript.

48 All authors approved the final manuscript as submitted and agree to be accountable for all

49 aspects of the work.

\section{INTRODUCTION}

Previous research documents that the ACA Medicaid expansions have increased health

53 insurance coverage among low-income parents. ${ }^{1-5}$ Though children in low-income households

54 were already eligible for health insurance coverage through Medicaid, the ACA Medicaid

55 expansions also increased health insurance coverage of these children through parents' increased

56 awareness of their children's eligibility for existing Medicaid coverage. ${ }^{6}$ Evidence is also building

57 showing the spillover effects of these expansions onto other parental outcomes including financial

58 well-being ${ }^{1,7}$ and psychological distress. ${ }^{1}$ Emerging research suggests that children also benefit

59 from adult Medicaid expansions in the form of more preventive care use ${ }^{8}$ and improved children's

60 reading skills. ${ }^{9}$

61 Less is known about how these increases in health insurance coverage and preventive care

62 have spillover effects on the health outcomes of parents and children, specifically. In general,

63 correlational research shows a positive relationship between parental insurance coverage and

64 children's health in low-income families. ${ }^{10-13}$ Causal research on whether health insurance

65 coverage affects overall health, however, is mixed. ${ }^{14-20}$

66 Although much research has shown improvements in health outcomes among the low-

67 income adult population from the ACA Medicaid expansions, ${ }^{21}$ it is important to distinguish

68 between adults without dependent children and parents given that parents are more likely to

69 subsequently influence children. Existing research that does not include parents may be missing a

70 feature of the ACA Medicaid expansion effects, namely spillover effects on children already

71 eligible for Medicaid coverage. Understanding the effects on children's healthcare utilization and 
72 health outcomes is important in documenting the impact of public health insurance eligibility for

73 low-income parents on their children's development.

74 In this study, we examine the spillover effects of public health insurance expansions for

75 low-income adults on parent and child health, extending the prior literature that showed positive

76 effects of parental health insurance expansions on children's health insurance outcomes. ${ }^{22,23} \mathrm{We}$

77 pair longitudinal data on a representative sample of children from low-income households with a

78 quasi-experimental design that leverages state variation in Medicaid expansion between 2010-

79 2016. We also examine heterogeneity in the findings by child race and ethnicity, child sex, and

80 family income due to potential differences in the spillover effects related to these demographic

81 characteristics. For example, due to the timing of maturation and differences in body composition

82 and healthcare needs, there may be differences in the role of parental public health insurance access

83 on health between girls and boys. Our findings document how changes in state Medicaid policies

84 regarding adult eligibility affect the health of parents and their children.

\section{METHODS}

\section{$87 \quad$ Data}

We analyze data from the Early Childhood Longitudinal Study, Kindergarten class of

89 2010-11 (ECLS-K:2011), a nationally representative cohort of U.S. children who entered

90 kindergarten in the fall of 2010. ECLS-K:2011 is sponsored by the National Center for Education

91 Statistics (NCES) within the Institute of Education Sciences (IES) of the U.S. Department of

92 Education. Follow up data on children, parents, and teachers were done 1-2 times per year between

932011 and 2016. The ECLS-K:2011 provides significant strengths in answering the research

94 questions; the data are nationally representative, were collected in multiple languages, and there is 
95 a sizable subsample of the population of interest, low-income families. The ECLS-K:2011 contains

96 strong measurement with parent reports of parent health, child health, and child health care

97 utilization, and direct assessments of children's body mass index (BMI). Most importantly, there

98 are several waves of data collected both before and after the ACA Medicaid expansions. Multiple

99 studies have utilized the ECSL-K:2011 to study child and parent health. ${ }^{24-26}$

100 We limit the analytical sample to households with incomes less than 138 percent of the

101 federal poverty line (FPL) in 2013 to focus on the households most likely to be eligible for the

102 ACA's expansion to low-income adults. We follow this group of children/parents pre- and post-

103 expansion - enabled by the longitudinal nature of data-to estimate the ACA impacts post-

104 expansion. Of the 14,530 children eligible for inclusion in spring 2016 data collection, 11,440

105 responded in spring 2016. Of these, 4,270 children were from low-income households who resided

106 in the same state across all waves. ${ }^{1}$ To account for the complex survey design and non-random

107 attrition across waves, we include post-stratification weights. In all, after accounting for missing 108 data on key variables of interest and zero longitudinal weights, our analytical sample size is 109 approximately 2,500 children across 7 waves, totaling 10,000-16,800 child-wave observations (the

110 exact sample size varies slightly across models). Thus, our results are generalizable to children in

111 low-income households in the U.S. who attended kindergarten in fall 2010. Additional detail

112 regarding the ECLS-K:2011's study design is available from the NCES. We obtained Penn State 113 Institutional Review Board approval for the study.

\section{Measures}

\footnotetext{
${ }^{1}$ To keep the comparisons clean we drop the children who moved across state lines across waves in our data. Only 30 movers had non-missing responses on our key variables of interest precluding any independent analysis of the subsample of movers.
} 
117 the previous literature that has explored the impact of public health expansions for children in the 118 1990s on children's health status and health utilization. ${ }^{27,28}$ In addition, we include a measure of 119 overall parental health status in our analysis. Specifically, we assess the following:

120 (1) Parent Health. Parents reported on their overall health status on a 5-point scale $(1=$ 121 Excellent, 2=Very Good, 3=Good, 4=Fair, and $5=$ Poor $)$ in each wave. Following past literature, ${ }^{27}$ we convert this measure to a binary variable to indicate whether the parent is in good health or better (over $80 \%$ of parents fall into this category).

(2) Child Health. Parents also reported on their children's overall health status on a 5point scale $(1=$ Excellent, $2=$ Very Good, $3=$ Good, $4=$ Fair, and $5=$ Poor $)$ in each wave. Similar to the parental health measure, we convert this measure to a binary variable to indicate whether the child is in good health or better (over $90 \%$ of children fall into this category).

(3) Child health utilization for routine care. To investigate the effect of public health insurance expansions on children's healthcare utilization, we assess whether a child had any doctor visits for routine care in the past year. We focus on utilization that is explicitly routine in nature to avoid confounding between healthcare access and sickness, following previous literature. ${ }^{28}$ Specifically, in each wave, parents were asked "How long has it been since [child's] last visit to a clinic, health center, hospital, doctor's office, or other place for routine care?". Parents reported on a 5-point scale (1 = Never, 2 = Less than 6 months, $3=6-12$ months, $4=1-2$ years, $5=$ greater than 2 years). Because the AAP recommends children have at least one preventative/routine 
doctor's visit per year, ${ }^{29}$ we recode this variable as binary equaling 1 if the child had at least 1 doctor visit in the past year, and zero otherwise.

(4) Child Body Mass Index (BMI). In addition to the self/parent-reported measures of health and healthcare utilization, we include an objectively assessed measure of child health: child BMI. To ensure accurate measurements, children's weight and height measurements were carried out twice. Composite BMI measures (calculated as weight in kilograms divided by height in meters squared) were provided for each wave in the data. Because we are using a longitudinal model to assess within-child changes in BMI, we use the composite BMI measures in our main analyses. ${ }^{2}$

147 Table 1 shows the weighted and unweighted descriptive characteristics of the key measures 148 from our analytic sample.

${ }^{2}$ See appendix for results and discussion on why BMI z-scores (calculated using age- and sex-specific CDC growth charts) are not well-suited for this analysis. ${ }^{30,31}$ 


\begin{tabular}{|c|c|c|c|c|c|c|c|}
\hline & \multicolumn{3}{|c|}{ All States } & \multirow{2}{*}{$\begin{array}{c}\begin{array}{c}\text { Non- } \\
\text { Expansion } \\
\text { States }\end{array} \\
\text { Mean }\end{array}$} & \multirow{2}{*}{$\begin{array}{c}\begin{array}{c}\text { Expansion } \\
\text { States }\end{array} \\
\text { Mean }\end{array}$} & \multirow{2}{*}{$\begin{array}{c}\text { Non- } \\
\text { Expansion } \\
\text { States } \\
\text { Weighted } \\
\text { Mean }\end{array}$} & \multirow{2}{*}{$\begin{array}{c}\text { Expansion } \\
\text { States }\end{array}$} \\
\hline & $N^{\mathrm{a}}$ & Mean & $S D$ & & & & \\
\hline \multicolumn{8}{|l|}{ Parental Health } \\
\hline $\begin{array}{l}\text { Overall Health Status } \\
\text { (Good or better) }\end{array}$ & 14,870 & 0.815 & 0.388 & 0.795 & 0.834 & 0.786 & 0.848 \\
\hline \multicolumn{8}{|l|}{$\begin{array}{c}\text { Child Health } \\
\text { Utilization }\end{array}$} \\
\hline $\begin{array}{l}\text { At least } 1 \text { Routine } \\
\text { Doctor Visit in past } \\
\text { year }\end{array}$ & 15,880 & 0.888 & 0.315 & 0.900 & 0.876 & 0.902 & 0.875 \\
\hline \multicolumn{8}{|l|}{ Child Health } \\
\hline $\begin{array}{l}\text { Overall Health Status } \\
\text { (Good or better) }\end{array}$ & 21,930 & 0.953 & 0.212 & 0.947 & 0.959 & 0.949 & 0.963 \\
\hline BMI & 25,930 & 18.501 & 4.176 & 18.613 & 18.392 & 18.835 & 18.497 \\
\hline \multicolumn{8}{|c|}{ Family and Child Characteristics } \\
\hline Male & 26,900 & 0.514 & 0.499 & 0.522 & 0.506 & 0.527 & 0.501 \\
\hline Black & 26,900 & 0.159 & 0.366 & 0.226 & 0.096 & 0.262 & 0.130 \\
\hline Hispanic & 26,900 & 0.466 & 0.498 & 0.430 & 0.500 & 0.374 & 0.459 \\
\hline White & 26,900 & 0.252 & 0.434 & 0.265 & 0.239 & 0.287 & 0.300 \\
\hline Child age (in months) & 26,900 & 96.723 & 22.506 & 96.514 & 96.922 & 98.127 & 98.553 \\
\hline Parent age (in years) & 26,900 & 32.067 & 7.752 & 31.696 & 32.474 & 31.972 & 32.776 \\
\hline $\begin{array}{l}\text { Parent has high school } \\
\text { diploma or more }\end{array}$ & 26,900 & 0.328 & 0.469 & 0.331 & 0.323 & 0.358 & 0.345 \\
\hline \multicolumn{8}{|l|}{$\begin{array}{l}\text { Time-varying State } \\
\text { Characteristics }\end{array}$} \\
\hline Unemployment rate & 26,900 & 7.331 & 2.163 & 6.849 & 7.789 & 6.721 & 7.580 \\
\hline EITC rate & 26,900 & 0.073 & 0.154 & 0.020 & 0.123 & 0.021 & 0.119 \\
\hline $\begin{array}{l}\text { TANF/SNAP max. } \\
\text { benefits for family } \\
\text { of } 3(\$)\end{array}$ & 26,900 & 942.50 & 183.46 & 809.00 & 1069.16 & 811.39 & 1052.16 \\
\hline Minimum wage & 26,900 & 7.615 & 0.792 & 7.208 & 8.002 & 7.098 & 7.976 \\
\hline
\end{tabular}

Notes: The difference between expansion and non-expansion states is statistically significant at $p$ $<.05$ for all variables. Sampling weights are used in the last two columns to adjust for nonresponse and differential attrition across waves in the sampling a Sample sizes (in childwaves) are rounded to the nearest 10 as per dataset guidelines. 
159 states. $^{3}$ Past literature has shown that the states that expanded were more progressive; these 160 statistical differences underscore the need to use an appropriate identification strategy in our

161 analysis to account for these differences. Indeed, we use a difference-in-differences (DD) approach

162 precisely to ensure that these differences in levels can be accounted for by focusing on the

163 differences in the trends of these outcomes pre- and post-ACA between expansion and non-

164 expansion states. We describe our analytical approach below.

\section{Analytic Method}

Although the ACA was originally a federal mandate, in 2012, the Supreme Court allowed

167 states to opt out of the Medicaid expansion requirement. As a result, some states opted to expand

168 Medicaid to all adults with household incomes less than 138\% FPL, while some states did not. In

169 our analytic sample, children (and parents) who reside in twenty-five states are coded as 1 to denote

170 expansion and those in the remaining sixteen states are coded as 0 . Table S1 shows details of

171 states' expansion decisions. Due to ECLS-K:2011's clustered sampling framework, there were no

172 children sampled from 10 states.

173 Using a child's state of residence and the date in which that state expanded Medicaid

174 through the ACA, we employ a DD approach to estimate the impact of the public health insurance

175 expansions for low-income adults on parents' health, children's health, and children's use of

176 routine health services (see Appendix for supplemental information regarding the models and

177 methods). Specifically, we compare the changes in health outcomes of children (and parents) from

178 before the Medicaid expansion (waves 1-4, when children entered kindergarten through the spring

179 of second grade) and after the expansion in January 2014 (waves 5-7, when children were in third

\footnotetext{
${ }^{3}$ These statistical differences persist even in the weighted means comparisons. It is however important to note that the sampling weights primarily adjust for nonresponse bias and differential attrition in the survey sample design. So, these weights are not intended to balance the treatment and comparison means to account for selection bias.
} 
180 through fifth grades) between the expansion and non-expansion states. Children are coded as being

181 in the treatment group (post-expansion) if their state of residence expanded during or after 2014.

182 Although most states expanded their Medicaid programs to low-income adults in 2014, some states

183 expanded early, and some expanded late. Early expanders are treated as if they expanded in 2014

184 based on the effective date of expansion, meaning all time points prior to 2014 (waves 1-4) are

185 coded as not yet expanded. We use 2014 as the effective date of expansion even for the early

186 expanders, as is standard in the past ACA literature, because full implementation took place only

187 2014-onwards. ${ }^{20,21} \mathrm{We}$ also include child fixed effects, which adjust for all time-invariant factors

188 related to the outcomes of interest, including a child's sex, race/ethnicity, parent education, and

189 other constant household characteristics and unobserved features.

190 In addition, we adjust for several time-varying state characteristics that may have

191 differentially affected the health and healthcare utilization outcomes across states in low-income

192 households. Because these factors may also be correlated with a state's decision to expand

193 Medicaid for low-income adults, adjusting for these factors helps reduce time-varying confounds.

194 Specifically, we include the following characteristics: state unemployment rates, state Earned

195 Income Tax Credit (EITC) rates, state minimum wages, and the maximum Temporary Assistance

196 for Needy Family (TANF) and Supplemental Nutrition Assistance Program (SNAP) combined

197 benefits for a family of three at the state-year level.

198 We use Ordinary Least Squares (OLS) estimation for all our models. Because the 199 dependent variables, other than BMI, are all binary, they are linear probability models in such 200 cases and the reported coefficient can be interpreted as marginal effects (i.e., percentage point 201 changes in outcomes in expansion states post-expansion). All statistical analyses are weighted to 
202 adjust for sampling procedures, nonresponse, differential attrition, and standard errors are

203 clustered at the state level, the level at which treatment status varies. ${ }^{32}$

\section{RESULTS}

205

206

207

209

210

212

213

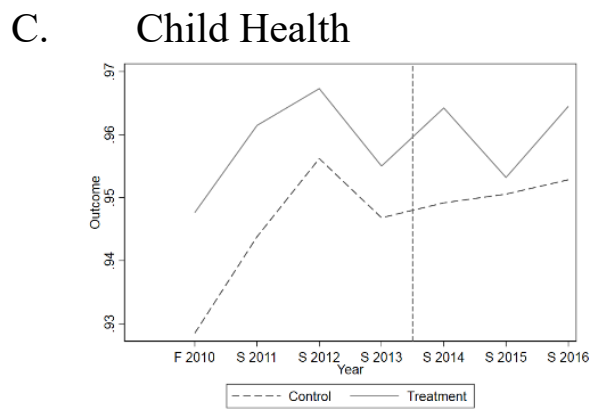

A. Parent Health

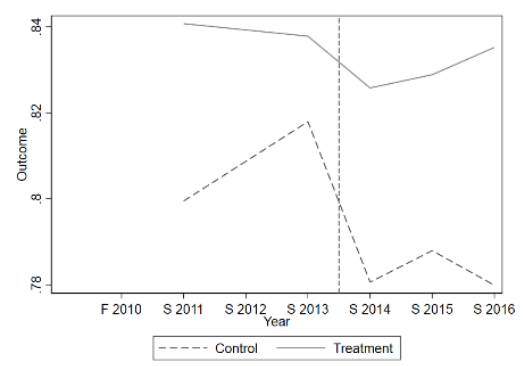

B. Child Health Utilization

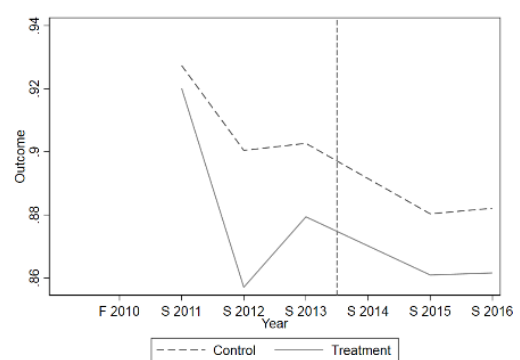

Figure 1. Raw Trends in Variables of Interest

215

Notes: Data from ECLS:K 2011. Expansion states are the treatment states, and non-expansion
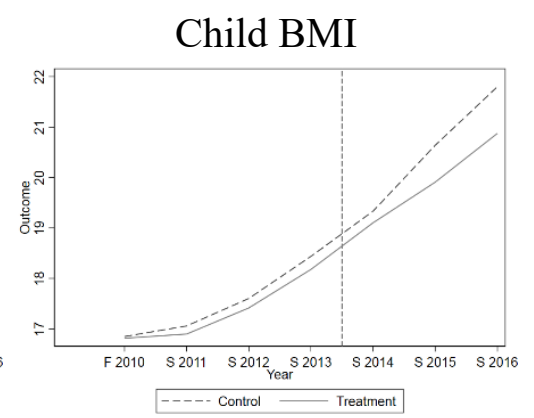
Figure 1 shows the summarized health trajectories over the study period for parents and

223 children in the expansion states relative to non-expansion states among low-income households.

224 Across these dependent variables, we observe largely parallel trends prior to the expansion

225 (January 2014). We test this more rigorously in the appendix, where we provide (1) results from

226 regression-adjusted models that show that the linear pre-trends in our models are not statistically

227 different between the two groups of states prior to the expansion (see Table S2); and event-study

228 graphs (see Figure S1) that provide further confidence in the DD identification strategy.

229 Table 2. Impact of the ACA Medicaid Expansion on Health Outcomes in Low-Income

230 Households $(<\mathbf{1 3 8 \%}$ FPL)

231

\begin{tabular}{|c|c|c|c|c|}
\hline A. Parent Health & \multicolumn{2}{|c|}{ Overall Health } & & \\
\hline & $(1)$ & $(2)$ & & \\
\hline \multirow[t]{2}{*}{ Expansion } & $0.039 * * *$ & $0.034 *$ & & \\
\hline & $(0.010)$ & $(0.013)$ & & \\
\hline Mean of DV & 0.829 & 0.829 & & \\
\hline Time Varying State Covariates & No & Yes & & \\
\hline Observations $^{\text {a }}$ & 10,760 & 10,760 & & \\
\hline R-squared (within-child) & 0.004 & 0.005 & & \\
\hline \multirow[t]{2}{*}{ B. Child Health Utilization } & \multicolumn{2}{|c|}{ Doctor Visits } & & \\
\hline & $(1)$ & $(2)$ & & \\
\hline \multirow[t]{2}{*}{ Expansion } & -0.003 & 0.011 & & \\
\hline & $(0.013)$ & $(0.014)$ & & \\
\hline Mean of DV & 0.92 & 0.92 & & \\
\hline Time Varying State Covariates & No & Yes & & \\
\hline Observations $^{\text {a }}$ & 11,160 & 11,160 & & \\
\hline R-squared (within-child) & 0.008 & 0.009 & & \\
\hline \multirow[t]{2}{*}{ C. Child Health } & \multicolumn{2}{|c|}{ Overall Health } & \multirow{2}{*}{\multicolumn{2}{|c|}{ BMI }} \\
\hline & (1) & (2) & & \\
\hline \multirow[t]{2}{*}{ Expansion } & -0.007 & -0.004 & $-0.443 * *$ & $-0.334^{*}$ \\
\hline & $(0.007)$ & $(0.009)$ & $(0.133)$ & $(0.142)$ \\
\hline Mean of DV & 0.94 & 0.94 & 16.88 & 16.88 \\
\hline Time Varying State Covariates & No & Yes & No & Yes \\
\hline Observations $^{\text {a }}$ & 15,300 & 15,300 & 16,840 & 16,840 \\
\hline R-squared (within-child) & 0.002 & 0.002 & 0.471 & 0.473 \\
\hline
\end{tabular}

232 Notes: Each column of each panel corresponds to a different OLS regression model. Each model

233 includes wave and child fixed effects and sampling weights. Expansion represents $\beta_{1}$ from 
234 equation (1) as shown in appendix, and measures the average effect of the Medicaid expansions

235 after it took place. Mean of each dependent variable (DV) provides the within-child average of

236 the DV after controlling for just wave fixed effects. Heteroscedasticity-robust standard errors, in

237 parentheses, are clustered at the state level.

$238{ }^{a}$ Sample sizes (in child-years) are rounded to the nearest 10 as per dataset guidelines.

$239 * p<0.05, * * p<0.01, * * * p<0.001$.

Table 2 reports the main estimates of the effect of the ACA's public health insurance

242 expansions to low-income adults on parent and child health outcomes. Model 1 (column 1)

243 includes child fixed effects, wave fixed effects, and the time-varying expansion status at the state

244 level (see Table S1 for the expansion status). In Model 2 (column 2), we add the time-varying 245 state-level covariates to the DD regression models.

246 First, we find that parents who reside in expansion states reported overall better health post-

247 expansion. On average, we observe a 3.9 percentage point increase of parents who report "good",

248 "very good", or "excellent" health as compared to those in non-expansion states. These health

249 effects persist in model 2 despite inclusion of other potential time-varying confounding variables.

250 Relative to the mean value of 0.829 , this increase represents an improvement of about 4.7 percent.

251 Next, we examine if these effects extend to children's health utilization and health. Panel

252 B reports no statistically significant changes in routine doctor visits for children or parents'

253 assessment of their child's overall health. In contrast, as shown in Panel C, we observe significant

254 decreases in children's BMI. These effects are modest (about 2\%). Interestingly, we observe that

255 the BMI decreases are driven by girls (see Table S3 for more heterogenous effects).

256 SENSITIVITY ANALYSES

257 To confirm that omitted variables are not driving the main results, we next perform a

258 placebo check. We conduct the same difference-in-differences analysis using a sample of

259 households with household incomes above 400\% FPL. We do not expect parents and children in 
260 these households to be affected by the Medicaid expansions since the adults in the households

261 were not eligible due to their higher incomes. Indeed, Table 3 reports no significant effects for any

262 of the health or healthcare use outcomes for this high-income sample.

263 Table 3. Impact of the ACA Medicaid Expansion on Health Outcomes in High-Income

264 Households (> 400\% FPL)

\begin{tabular}{|c|c|c|c|c|}
\hline \multirow{2}{*}{ A. Parent Health } & \multicolumn{2}{|c|}{ Overall Health } & & \\
\hline & (1) & (2) & & \\
\hline \multirow[t]{2}{*}{ Expansion } & -0.004 & -0.009 & & \\
\hline & $(0.007)$ & $(0.007)$ & & \\
\hline Mean of DV & 0.963 & 0.963 & & \\
\hline Time Varying State Covariates & No & Yes & & \\
\hline Observations $^{\text {a }}$ & 11,730 & 11,730 & & \\
\hline R-squared (within-child) & 0.002 & 0.003 & & \\
\hline \multirow[t]{2}{*}{ B. Child Health Utilization } & \multicolumn{2}{|c|}{ Doctor Visits } & & \\
\hline & (1) & (2) & & \\
\hline \multirow[t]{2}{*}{ Expansion } & -0.004 & 0.014 & & \\
\hline & $(0.015)$ & $(0.017)$ & & \\
\hline Mean of DV & 0.94 & 0.93 & & \\
\hline \multirow{2}{*}{$\begin{array}{l}\text { Time Varying State Covariates } \\
\text { Observations }^{\text {a }}\end{array}$} & No & Yes & & \\
\hline & 11,910 & 11,910 & & \\
\hline R-squared (within-child) & 0.013 & 0.015 & & \\
\hline \multirow[t]{2}{*}{ C. Child Health } & \multicolumn{2}{|c|}{ Overall Health } & \multicolumn{2}{|c|}{ BMI } \\
\hline & $(1)$ & $(2)$ & (1) & (2) \\
\hline \multirow[t]{2}{*}{ Expansion } & 0.007 & 0.006 & 0.021 & 0.153 \\
\hline & $(0.004)$ & $(0.004)$ & $(0.091)$ & $(0.117)$ \\
\hline Mean of DV & 0.98 & 0.98 & 16.26 & 16.26 \\
\hline Time Varying State Covariates & No & Yes & No & Yes \\
\hline Observations ${ }^{\text {a }}$ & 16,590 & 16,590 & 18,190 & 18,190 \\
\hline R-squared (within-child) & 0.001 & 0.002 & 0.445 & 0.449 \\
\hline
\end{tabular}

265 Notes: Each column of each panel corresponds to a different OLS regression model. Each model

266 includes wave and child fixed effects, state-level covariates, and sampling weights. Expansion

267 represents $\beta_{1}$ from equation (1) as shown in appendix, estimated for sub-sample of higher-

268 income ( $>400 \%$ FPL households only), and measures the average effect of the Medicaid

269 expansions after it took place. Mean of each dependent variable (DV) provides the within-child

270 average of the DV after controlling for just wave fixed effects. Heteroscedasticity-robust

271 standard errors, in parentheses, are clustered at the state level.

$272{ }^{a}$ Sample sizes (in child-years) are rounded to the nearest 10 as per dataset guidelines.

$273 * p<0.05, * * p<0.01, * * * p<0.001$. 
Next, we perform a similar analysis on a more precise subset of households in states that

276 expanded. Specifically, we limit the sample to households with incomes between each state's pre-

277 ACA parental eligibility income thresholds and 138\% FPL. Unlike the main analysis, in which we

278 treat all households with incomes under 138\% FPL in expansion states as being "treated," in this

279 analysis we focus only on parents who were most likely to be newly eligible under the ACA due

280 to their parental status. On average, the Medicaid eligibility threshold for parents in expansion

281 states increased from about 105\% in 2011 (unweighted average across expansion states) to at least

282 138\% in 2014 under the ACA (see Appendix Table S5 for details on the thresholds we used). We

283 also include more details regarding the models and methods for this robustness analysis in the

284 appendix.

285 As this is a more precise sample, we expect the effects to be tighter. Parents and children

286 in low-income households $(<138 \%$ FPL $)$ residing in states that did not expand Medicaid through

287 the ACA consist of the control group, as before. Children whose parents were eligible for Medicaid 288 based on pre-ACA income thresholds in expansion and non-expansion states are dropped. All other

289 elements remain the same as in the main estimation. Table 4 reports results from this analysis.

290 Because we have more limited sample size and fewer treatment clusters here, we also report wild

291 cluster bootstrapped p-values here..$^{33,34}$

292 Table 4. Impact of the ACA Parental Income Eligibility Expansion on Impact of the ACA 293 Medicaid Expansion on Health Outcomes in Low-Income Households (<138\% FPL)

\begin{tabular}{lcc}
\hline A. Parent Health & \multicolumn{2}{c}{ Overall Health } \\
\hline Expansion & $(1)$ & $(2)$ \\
& $0.063^{* * *}$ & $0.062^{* * *}$ \\
Mean of DV & $(0.018)$ & $(0.017)$ \\
Time Varying State Covariates & 0.839 & 0.839 \\
Observations ${ }^{\text {a }}$ & No & Yes \\
R-squared (within-child) & 5,240 & 5,240 \\
Wild Cluster Bootstrap p-value & 0.005 & 0.006 \\
\hline
\end{tabular}




\begin{tabular}{|c|c|c|c|c|}
\hline \multirow[t]{2}{*}{ B. Child Health Utilization } & \multicolumn{2}{|c|}{ Doctor Visits } & & \\
\hline & (1) & (2) & & \\
\hline \multirow[t]{2}{*}{ Expansion } & -0.025 & -0.010 & & \\
\hline & $(0.018)$ & $(0.020)$ & & \\
\hline Mean of DV & 0.94 & 0.94 & & \\
\hline \multirow{2}{*}{$\begin{array}{l}\text { Time Varying State Covariates } \\
\text { Observations }^{\text {a }}\end{array}$} & No & Yes & & \\
\hline & 5,390 & 5,390 & & \\
\hline \multirow{2}{*}{$\begin{array}{l}\text { R-squared (within-child) } \\
\text { Wild Cluster Bootstrap p-value }\end{array}$} & 0.010 & 0.013 & & \\
\hline & 0.807 & 0.812 & & \\
\hline \multirow[t]{2}{*}{ C. Child Health } & \multicolumn{2}{|c|}{ Overall Health } & \multicolumn{2}{|c|}{ BMI } \\
\hline & (1) & (2) & (1) & (2) \\
\hline \multirow[t]{2}{*}{ Expansion } & -0.002 & 0.007 & $-0.444 *$ & $-0.486^{*}$ \\
\hline & $(0.009)$ & $(0.009)$ & $(0.183)$ & $(0.192)$ \\
\hline Mean of DV & 0.95 & 0.95 & 16.91 & 16.91 \\
\hline Time Varying State Covariates & No & Yes & No & Yes \\
\hline Observations ${ }^{\text {a }}$ & 7,430 & 7,430 & 8,140 & 8,140 \\
\hline R-squared (within-child) & 0.002 & 0.002 & 0.458 & 0.459 \\
\hline Wild Cluster Bootstrap p-value & 0.817 & 0.631 & 0.048 & 0.066 \\
\hline
\end{tabular}

Notes: Each column of each panel corresponds to a different OLS regression model. Each model

295 includes wave and child fixed effects and sampling weights. Expansion represents $\beta$ from

296 equation (2), as shown in appendix, and measures the average effect of the Medicaid expansions 297 after it took place. Mean of each dependent variable (DV) provides the within-child average of 298 the DV after controlling for just wave fixed effects. Heteroscedasticity-robust standard errors, in parentheses, are clustered at the state level. a Sample sizes (in child-years) are rounded to the nearest 10 as per dataset guidelines. ${ }^{*} \mathrm{p}<0.05,{ }^{* *} \mathrm{p}<0.01,{ }^{* * *} \mathrm{p}<0.001$. We also report wild cluster bootstrapped $p$-values in the last row within each panel created using "boottest" command in STATA with 1,000 replications, which provides more conservative standard errors for inference in Table 4 (Cameron \& Miller, 2008; 2015).

As expected, we find larger effects on self-reported overall parental health. Specifically,

307 percentage points ( $\sim 7 \%$ compared to $\sim 4.7 \%$ in the main analysis). The effects on children's BMI

308 (Panel C) are approximately the same size (3\%), and the insignificant findings for doctor visits

309 and overall child health remain. Despite a reduction in precision when adjusted for fewer

310 clusters, the results on parent health and child BMI are qualitatively similar (ps $<0.10$ ). 
313 and fixed effects specifications; (3) and the examination of the role of staggered treatment timing

314 on our baseline estimates. While we do not find any statistically significant effects on children's

315 classification of being overweight, underweight, or obese; our baseline results on parent health

316 and child BMI are robust and qualitatively similar to alternative sample selections (such as

317 households with less than 100\% FPL, households where parents do not have a college-degree)

318 and the exclusion of individual fixed effects (see Table S6). Finally, we find that 92 percent of

319 our DD estimate of parent health and 93.5 percent of our DD estimate on child BMI comes from

320 comparisons of treated and never treated cohorts. This reduces the concerns regarding the role of

321 staggered treatment timing in our sample that the latest methodological advances in the applied

322 DD literature have highlighted (See Appendix for more details).

323

\section{DISCUSSION}

325 We investigated how recent public health insurance expansions for adults in low-income

326 households through the ACA affected the health of parents and their children. Using longitudinal

327 data on a large, nationally representative cohort of kindergarteners from low-income households

328 from 2010-2016, we found that parents' self-reported health status improved significantly post-

329 expansion in states that expanded their Medicaid programs to low-income adults. However, we

330 did not observe any significant changes in children's healthcare utilization (measured by a routine

331 doctor visit in the past year) or parents' assessment of their children's health status. We also

332 observed modest significant decreases in children's BMI, especially for girls. We first

333 contextualize the parental health effects and discuss the likely mechanisms that might be at play,

334 and then turn our focus to interpreting the child health effects on BMI. 
Although some low-income parents were eligible for public health insurance prior to the 336 ACA based on varying state eligibility rules, many gained eligibility as a result of the ACA. 337 Specifically, Medicaid/CHIP insurance rates among low-income parents in expansion states 338 increased by about 12 percentage points by 2015 (in the first two years post-ACA). ${ }^{18}$ Research has 339 also documented increased financial security from such insurance coverage and better parent 340 health. ${ }^{18,35}$ Studies examining the impact of greater access to Medicaid in the 1990s and 2000s for 341 low-income parents found improvements in parental use of preventive medical care ${ }^{36}$ and their 342 reports of mental health. ${ }^{37}$ Unfortunately, the data do not allow us to examine the impact of ACA 343 expansions on health insurance coverage among low-income parents; nevertheless, our results on 344 improved parental health is consistent with prior research. By extending data in our sample through 345 the spring of 2016, we find that the immediate positive parental health effects (albeit not 346 significant ${ }^{18}$ found in the ACA literature seem to be sustained beyond the initial years post-ACA

347 implementation. We also find that the effects are stronger among Black, and below-median income 348 households in this low-income sample (see Appendix Table S3). However, we interpret these 349 heterogeneous findings with caution given low sample size for subsamples.

350 With respect to the spillovers on children's health utilization and overall health status, we 351 do not find significant changes. It is important to note that all children in our sample were likely 352 eligible for public health insurance for multiple years prior to the ACA unlike their parents. With 353 over 90 percent of these children receiving the recommended doctor visits and reporting good 354 health status, it is perhaps not surprising to see that the parental health insurance expansions 355 through the ACA did not have additional extensive margin effects on healthcare utilization or 356 parent-rated overall child health status. Further, because we adjust for child fixed effects, only 357 within-child variation pre- and post-ACA in these outcomes are captured in our final models which 
358 also exert some ceiling effects. Finally, because both these measures are parent-reported, we also

359 note the limitations regarding their subjective nature despite their widespread use in past

360 literature. $^{27,28}$

361 Yet, in an objectively measured health outcome - childhood BMI, previously unexplored

362 in the ACA literature - we document small protective effects of parental Medicaid eligibility.

363 Specifically, the ACA Medicaid expansions reduced BMI, especially among girls. These effects

364 are important since preventing excessive weight gain for school-aged children has been a focus of

365 school-based public health interventions, ${ }^{38}$ due to its links to adult obesity and other deleterious

366 effects across life-course. ${ }^{39,40}$ However, research has also shown that factors outside schools-

367 specifically, parents and home environments - play a more prominent role in BMI changes for

368 school-aged children. ${ }^{26,41,42}$ Parents may be making improved nutritional dietary choices and food-

369 related routines for themselves and their children due to reduced stress. ${ }^{33,34}$ Improvements in

370 family income and economic well-being as a result of Medicaid coverage $e^{7,18}$ might also enable

371 low-income households to afford healthier food purchases. ${ }^{35}$ Indeed, family income is considered

372 a key social determinant of childhood obesity. ${ }^{36}$ We also examined sex differences in the effects

373 of the expansions on children's BMI because of documented sex differences in the social and

374 behavioral risk factors for overweight and obesity in childhood. ${ }^{44} \mathrm{We}$ found stronger BMI declines

375 among girls relative to boys. These results coincide with existing research finding a stronger

376 association between food insecurity and childhood BMI for girls, ${ }^{45,46}$ perhaps due to sex differences

377 in response to stress and parental feeding practices. ${ }^{47,48}$

378 Our study has some limitations. Although we did not randomly assign Medicaid eligibility

379 to parents in the sample as in a randomized control trial, we used a quasi-experimental design to

380 isolate the effect of adult Medicaid eligibility. Because there may be omitted, time-varying 
381 variables that are correlated with both our health outcomes and whether a state expanded their

382 Medicaid program, we use a variety of robustness checks to address this concern-including the

383 use of both child fixed effects and wave fixed effects (so that only within-child variation, before

384 and after the expansion could be driving the results), alternative sample exclusion strategy to

385 identify precise set of parents who likely became newly eligible for Medicaid under the ACA, and 386 placebo checks.

387 Our measures include parental self-report of their own health status and that of their 388 children. While we acknowledge the potential bias in self-report, this single item self-rating of 389 global health status has been used extensively in national surveys across multiple countries and 390 shows strong reliability and discriminant validity in terms of health conditions, use of health 391 services, and mortality. ${ }^{49}$ We also include direct assessments of children's BMI, which is less 392 subject to desirable response bias. Additionally, because the ECLS-K survey focuses on children, 393 parental health measures that are consistently included across waves are limited to self-rated 394 health. Future research should examine other parental health outcomes as well. Finally, we have 395 three post-expansion waves in the dataset. Therefore, our results reflect only the short-term effects. 396 Longer-term effects may be compounded given the importance of childhood health and the role of 397 parents' health in long-term gains.

398 Despite these limitations, these findings are important given the ongoing policy debates 399 regarding changes to the ACA and the precarious and uncertain nature of the post-COVID-19 400 pandemic job market and the role of employer-sponsored health care. In particular, understanding 401 the scope of the domains and populations in which the Medicaid expansions reach is important for 402 accurately documenting the costs and benefits of Medicaid. Finally, this research also provides 403 further evidence of a spillover of adult public health insurance eligibility onto children. 
405 CONCLUSION

406 We document that the ACA's Medicaid expansions for low-income adults improved 407 parents' self-rated health and children's BMI. Given the health disparities that persist across the 408 socioeconomic spectrum and the compounding nature of health improvements in childhood, the 409 Medicaid program likely serves to shrink these gaps within states that expanded their Medicaid 410 programs. These findings also indicate that there is the potential to reduce similar health disparities

411 in states that have not yet expanded their Medicaid programs to low-income adults through the 412 ACA.

413

414 


\section{REFERENCES}

416 1. McMorrow S, Gates JA, Long SK, Kenney GM. Medicaid expansion increased coverage, improved affordability, and reduced psychological distress for low-income parents. Health Affairs. 2017;36(5):808-818.

419 2. Kaestner R, Garrett B, Chen J, Gangopadhyaya A, Fleming C. Effects of ACA Medicaid expansions on health insurance coverage and labor supply. Journal of Policy Analysis and Management. 2017;36(3):608-642. doi:10.1002/pam.21993

3. Johnston EM, Strahan AE, Joski P, Dunlop AL, Adams EK. Impacts of the Affordable Care

5. Wherry LR. State Medicaid Expansions for Parents Led to Increased Coverage and Prenatal

7. Wisk LE, Peltz A, Galbraith AA. Changes in Health Care-Related Financial Burden for US

6. Hudson JL, Moriya AS. Medicaid Expansion For Adults Had Measurable 'Welcome Mat' Effects On Their Children. Health Affairs. 2017;36(9):1643-1651. doi:10.1377/hlthaff.2017.0347 Families With Children Associated With the Affordable Care Act. JAMA Pediatrics. 2020;174(11):1032-1040. doi:10.1001/jamapediatrics.2020.3973

8. Venkataramani M, Pollack CE, Roberts ET. Spillover Effects of Adult Medicaid Expansions on Children's Use of Preventive Services. Pediatrics. 2017;140(6). doi:10.1542/peds.2017-0953

9. Bullinger LR, Gopalan M, Lombardi C. Impacts of Publicly Funded Health Insurance for Adults on Children's Academic Achievement.; in prep.

10. Davidoff A, Dubay L, Kenney G, Yemane A. The effect of parents' insurance coverage on access to care for low-income children. INQUIRY: The Journal of Health Care Organization, Provision, and Financing. 2003;40(3):254-268.

11. Gifford EJ, Weech-Maldonado R, Short PF. Low-Income Children's Preventive Services Use: Implications of Parents' Medicaid Status. Health Care Financ Rev. 2005;26(4):81-94. Accessed March 15, 2021. https://www.ncbi.nlm.nih.gov/pmc/articles/PMC4194911/

12. DeVoe JE, Tillotson CJ, Wallace LS. Children's Receipt of Health Care Services and Family Health Insurance Patterns. The Annals of Family Medicine. 2009;7(5):406-413. doi:10.1370/afm.1040 
13. Wallace J, Sommers BD. Health Insurance Effects on Preventive Care and Health: A Methodologic Review. American Journal of Preventive Medicine. 2016;50(5, Supplement 1):S27-S33. doi:10.1016/j.amepre.2016.01.003

14. Cotti C, Nesson E, Tefft N. Impacts of the ACA Medicaid expansion on health behaviors: Evidence from household panel data. Health Economics. 2019;28(2):219-244. doi:10.1002/hec.3838

15. Courtemanche C, Marton J, Ukert B, Yelowitz A, Zapata D. Early Effects of the Affordable Care Act on Health Care Access, Risky Health Behaviors, and Self-Assessed Health. Southern Economic Journal. 2018;84(3):660-691. doi:10.1002/soej.12245

16. Courtemanche C, Marton J, Ukert B, Yelowitz A, Zapata D. Effects of the Affordable Care Act on Health Care Access and Self-Assessed Health After 3 Years. INQUIRY. 2018;55:0046958018796361. doi:10.1177/0046958018796361

17. Courtemanche C, Marton J, Ukert B, Yelowitz A, Zapata D. Effects of the Affordable Care Act on Health Behaviors After 3 Years. Eastern Econ J. 2019;45(1):7-33. doi:10.1057/s41302-018-0119-4

18. McMorrow S, Gates JA, Long SK, Kenney GM. Medicaid expansion increased coverage, improved affordability, and reduced psychological distress for low-income parents. Health Affairs. 2017;36(5):808-818.

19. Simon K, Soni A, Cawley J. The Impact of Health Insurance on Preventive Care and Health Behaviors: Evidence from the First Two Years of the ACA Medicaid Expansions. J Pol Anal Manage. 2017;36(2):390-417. doi:10.1002/pam.21972

20. Sommers BD, Gunja MZ, Finegold K, Musco T. Changes in Self-reported Insurance Coverage, Access to Care, and Health Under the Affordable Care Act. JAMA. 2015;314(4):366-374. doi:10.1001/jama.2015.8421

21. Soni A, Wherry LR, Simon KI. How Have ACA Insurance Expansions Affected Health Outcomes? Findings From The Literature. Health Affairs. 2020;39(3):371-378. doi:10.1377/hlthaff.2019.01436

22. Dubay L, Kenney G. Expanding public health insurance to parents: effects on children's coverage under Medicaid. Health Services Research. 2003;38(5):1283-1302.

23. Hamersma S, Kim M, Timpe B. The Effect of Parental Medicaid Expansions on Children's Health Insurance Coverage. Contemporary Economic Policy. 2019;37(2):297-311.

24. Diep CS, Baranowski T, Kimbro RT. Acculturation and weight change in Asian-American children: Evidence from the ECLS-K:2011. Prev Med. 2017;99:286-292.

doi:10.1016/j.ypmed.2017.03.019 
25. Bednar S, Rouse K. The effect of physical education on children's body weight and human capital: New evidence from the ECLS-K:2011. Health Econ. 2020;29(4):393-405. doi: $10.1002 /$ hec. 3990

26. von Hippel PT, Workman J. From Kindergarten Through Second Grade, U.S. Children's Obesity Prevalence Grows Only During Summer Vacations. Obesity (Silver Spring). 2016;24(11):2296-2300. doi:10.1002/oby.21613

27. Thompson O. The long-term health impacts of Medicaid and CHIP. Journal of Health Economics. 2017;51:26-40. doi:10.1016/j.jhealeco.2016.12.003

28. Currie J, Decker S, Lin W. Has public health insurance for older children reduced disparities in access to care and health outcomes? Journal of Health Economics. 2008;27(6):1567-1581. doi:10.1016/j.jhealeco.2008.07.002

29. AAP COMMITTEE ON PRACTICE AND AMBULATORY MEDICINE, AAP BRIGHT FUTURES PERIODICITY SCHEDULE WORKGROUP. 2017 Recommendations for Preventive Pediatric Health Care. Pediatrics. 2017;139(4):e20170254. doi:10.1542/peds.2017-0254

30. Berkey CS, Colditz GA. Adiposity in Adolescents: Change in Actual BMI Works Better Than Change in BMI z Score for Longitudinal Studies. Annals of Epidemiology. 2007;17(1):44-50. doi:10.1016/j.annepidem.2006.07.014

31. Cole TJ, Faith MS, Pietrobelli A, Heo M. What is the best measure of adiposity change in growing children: BMI, BMI \%, BMI z -score or BMI centile? European Journal of Clinical Nutrition. 2005;59(3):419-425. doi:10.1038/sj.ejcn.1602090

32. Bertrand M, Duflo E, Mullainathan S. How Much Should We Trust Differences-inDifferences Estimates? The Quarterly Journal of Economics. 2004;119(1):249-275. Accessed September 11, 2018. https://www.jstor.org/stable/25098683

33. Cameron A, Gelbach J, Miller D. Bootstrap-Based Improvements for Inference with Clustered Errors. The Review of Economics and Statistics. 2008;90(3):414-427. Accessed May 10, 2021. https://econpapers.repec.org/article/tprrestat/v_3a90_3ay_3a2008_3ai_3a3_3ap_3a414427.htm

34. Cameron AC, Miller DL. A Practitioner's Guide to Cluster-Robust Inference. J Human Resources. 2015;50(2):317-372. doi:10.3368/jhr.50.2.317

35. Brantley E, Darden M, Ku L. Associations of Expanding Parental Medicaid Eligibility and Parental Health and Family Functioning. Academic Pediatrics. Published online July 26, 2021. doi:10.1016/j.acap.2021.07.017

36. Busch SH, Duchovny N. Family coverage expansions: Impact on insurance coverage and health care utilization of parents. Journal of Health Economics. 2005;24(5):876-890. 
37. McMorrow S, Kenney GM, Long SK, Goin DE. Medicaid Expansions from 1997 to 2009 Increased Coverage and Improved Access and Mental Health Outcomes for Low-Income Parents. Health Serv Res. 2016;51(4):1347-1367. doi:10.1111/1475-6773.12432

38. Story M, Kaphingst KM, French S. The role of schools in obesity prevention. Future Child. 2006;16(1):109-142. doi:10.1353/foc.2006.0007

39. Whitaker RC, Pepe MS, Wright JA, Seidel KD, Dietz WH. Early adiposity rebound and the risk of adult obesity. Pediatrics. 1998;101(3):E5. doi:10.1542/peds.101.3.e5

40. Wilson SE, Crosnoe R, Daniels K. Introduction to Special Issue on Obesity and the Family across the Life Course. Economics \& Human Biology. 2012;10(4):329-332. doi:10.1016/j.ehb.2012.05.003

41. von Hippel PT, Powell B, Downey DB, Rowland NJ. The Effect of School on Overweight in Childhood: Gain in Body Mass Index During the School Year and During Summer Vacation. Am J Public Health. 2007;97(4):696-702. doi:10.2105/AJPH.2005.080754

42. Anderson PM. Parental employment, family routines and childhood obesity. Economics \& Human Biology. 2012;10(4):340-351. doi:10.1016/j.ehb.2012.04.006

43. Ogden CL, Fryar CD, Hales CM, Carroll MD, Aoki Y, Freedman DS. Differences in Obesity Prevalence by Demographics and Urbanization in US Children and Adolescents, 2013-2016. JAMA. 2018;319(23):2410-2418. doi:10.1001/jama.2018.5158

44. Wisniewski AB, Chernausek SD. Gender in childhood obesity: Family environment, hormones, and genes. Gender Medicine. 2009;6:76-85. doi:10.1016/j.genm.2008.12.001

45. Casey PH, Simpson PM, Gossett JM, et al. The Association of Child and Household Food Insecurity With Childhood Overweight Status. Pediatrics. 2006;118(5):e1406-e1413. doi:10.1542/peds.2006-0097

46. Speirs KE, Fiese BH, STRONG Kids Research Team. The Relationship Between Food Insecurity and BMI for Preschool Children. Matern Child Health J. 2016;20(4):925-933. doi:10.1007/s10995-015-1881-0

47. Faith MS, Scanlon KS, Birch LL, Francis LA, Sherry B. Parent-Child Feeding Strategies and Their Relationships to Child Eating and Weight Status. Obesity Research. 2004;12(11):1711-1722. doi:10.1038/oby.2004.212

48. Jyoti DF, Frongillo EA, Jones SJ. Food Insecurity Affects School Children's Academic Performance, Weight Gain, and Social Skills. The Journal of Nutrition. 2005;135(12):28312839. doi:10.1093/jn/135.12.2831

49. Bowling A. Just one question: If one question works, why ask several? Journal of Epidemiology \& Community Health. 2005;59(5):342-345. doi:10.1136/jech.2004.021204 
556

557 


\section{Supplemental Information}

\section{DD Analysis}

The DD analysis we use in this study involves the estimation of a multivariate linear regression model of the form shown below.

(1) $Y_{i s t}=\beta_{0}+\beta_{1}$ MedicaidExpansion $_{s t}+\alpha_{i}+\gamma_{t}+\delta_{s}+\lambda^{\prime} X_{i}+\eta Z_{s t}+\varepsilon_{i s t}$

Where $Y_{\text {ist }}$ is the child or parent health outcome measured at each wave $t$. MedicaidExpansion $_{s t}$ is a binary variable equal to 1 if child $i$ lives in state $s$ that expanded Medicaid during wave $t$, and zero otherwise; $\alpha_{i}$ refers to child fixed effects that captures all time-invariant factors related to health, such as constant family characteristics and unobserved features; $\gamma_{t}$ refers to wave fixed effects that captures secular trends affecting all children over time; $Z_{s t}$ includes a vector of time-varying state-level covariates described earlier in the manuscript; and $\varepsilon_{\text {ist }}$ is the error term. The parameter of interest is $\beta_{1}$, which represents the effect of the ACA Medicaid expansion. Because the analytic sample only included children who did not move across states during the study period, state fixed effects $\left(\delta_{s}\right)$ and all time-invariant child- and familycharacteristics $\left(X_{i}\right)$ were subsumed by the child fixed effects $\left(\alpha_{i}\right)$ in these models. Because child fixed effects are included and expansion status is time-varying at the state-level, only within-child variation, post-expansion in outcomes is captured by $\beta_{1}$. All statistical analyses were weighted to adjust for sampling procedures, nonresponse, differential attrition, and standard errors were clustered at the state level as is standard in DD analysis because treatment status varies at the state level.

\section{State-level Medicaid Expansion Status}

As described in the main manuscript, although the ACA was originally a federal mandate, the Supreme Court allowed states to opt out of this requirement in 2012. As a result, some states 
opted to expand Medicaid to all adults with household incomes less than 138 percent FPL, while some states did not. In our study, children (and parents) who reside in twenty-five states are coded as 1 (in the waves post-expansion) to denote expansion and those in the remaining sixteen states are coded as 0 (in all waves). Table S1 shows details of states' expansion decisions. Most states expanded in 2014 and are coded as 1 in waves 5 (Spring 2014), 6 (Spring 2015) and 7 (Spring 2016), as is standard in DD analyses, for the baseline Table 2 results. States that expanded after 2014 are coded as 1 only in those relevant waves. For example, Pennsylvania expanded only in 2015, so is coded as 1 only in waves 6 (Spring 2015) and 7 (Spring 2016) as is standard in DD analyses, for the baseline results presented in Table 2. Due to ECLS-K:2011's clustered sampling framework, there were no children sampled from 10 states; nevertheless, ECLS-K:2011 is nationally-representative. See more details about ECLS-K:2011 here: https://nces.ed.gov/ecls/kindergarten2011.asp.

\section{Testing Pre-trends Assumption}

\section{Linear Pre-trends}

A key assumption of the DD analysis is that trends in health outcomes of children and parents residing in states that expanded Medicaid versus not would be similar prior to the expansion. The summarized graphs in Figure 1 of the manuscript show these trends. In Table S2, we provide results from regression-adjusted models that show that linear pre-trends in our models are not statistically different between the two groups of states prior to the expansion providing confidence in the DD identification strategy. Essentially, in this analysis, we restrict the sample to the pre-expansion time period only and report the results of the coefficient-Expansion $x$ Wave, which is an interaction between a binary variable representing whether a child resided in a state that expanded its Medicaid program (as shown in Table S1) and a linear wave term. The rest of 
the model specification is similar to (1), which also includes wave, child fixed effects, state-level covariates, and are weighted by sampling weights.

More rigorously, we also include event-study graphs below (see Figure S1). Essentially, in this model, we include indicator variables to denote whether a child/parent from a low-income household $(<138 \%$ FPL) resided in a state that expanded Medicaid at time $\mathrm{t}-\mathrm{j}$, for all integers $\mathrm{j}$ representing the number of years since the expansion. All coefficients are normalized to the year before the expansion (i.e. "-1" indicator). Again, all other model specifications are similar to (1), and include child fixed effects and sampling weights.

\section{Heterogeneity Analysis}

Benefits of parental health insurance expansions might not be equally shared across all populations given significant pre-existing health disparities across key sociodemographic subgroups. We examine heterogeneity in treatment effects by conducting three sets of subsample

analyses (1) by race/ethnicity; (2) sex; and (3) high/low income within the sample of low-income households for primary outcomes of interest in which we observed significant main effects (see Appendix Table S3). We find that the effect on children's BMI is primarily driven by white children, specifically girls. This might be consequential given that white girls experience more weight-related stigma in middle school. ${ }^{1,2}$ We also observe a larger improvement in parental health among Black and below-median income households in our analytical sample. These results suggest that the benefits of health insurance expansions might be reaching the most vulnerable families even within the low-income sample. However, it is important to interpret these results with caution due to small sample sizes.

\section{Additional Robustness Checks}

Differential Parental Eligibility Thresholds 
In our main models, we define our primary treatment status to include states that expanded Medicaid to low-income adults through the ACA (in 2014 and beyond). Prior to the ACA, however, states had different income thresholds for low-income parents, meaning that the generosity of the ACA Medicaid expansions varied across states that expanded. For example, in Colorado, parents whose household income was less than 106\% of the FPL were eligible for Medicaid in 2011. In Pennsylvania, only parents whose household income was less than $46 \%$ of the FPL were eligible for Medicaid in 2011. Both states expanded through the ACA and all adults whose household income was less than $138 \%$ of the FPL became newly eligible in 2014 . The expansion was likely more impactful in Pennsylvania than it was in Colorado because a larger sample of low-income parents in Pennsylvania became newly eligible. On the other hand, some states that had income eligibility thresholds for parents above 138\% FPL in 2011 actually lowered their thresholds to meet the federal 138\% level (e.g., Wisconsin).

We examine these differences in parental eligibility in this robustness check by redefining the analytical sample. Specifically, we estimate equation 1 using an analytical sample that only includes those children whose parents would have been newly eligible. In other words, we drop children whose parents were eligible for Medicaid based on pre-ACA income thresholds, from both expansion and non-expansion states. We calculate this measure using parental income eligibility limits in 2011 combined with whether they resided in a state that expanded or not. Appendix Table S4 shows each expansion state's parental income eligibility threshold in 2011. In this model, parents and children in low-income households $(<138 \%$ FPL $)$ that reside in states that did not expand Medicaid through the ACA consist of the control group. However, children and parents who were already eligible for Medicaid based on pre-ACA income thresholds in the expansion and non-expansion states are dropped from the analysis as the new ACA expansions 
likely changes their public health insurance eligibility less, ${ }^{1}$ if at all. Essentially, this analysis aims to isolate treatment effects on parent and child outcomes by focusing on parents who were most likely to be newly eligible under ACA, and on whom we would expect the effects to be the largest. In other words, in this robustness check, we estimate a DD model on a more precise analytical sample that includes children from low-income households that were most likely to be newly eligible for Medicaid under the ACA in expansion states and those who would have been newly eligible in non-expansion states had the states they reside in expanded under the ACA, making that comparison group a valid counterfactual. These results are described in the main manuscript as well.

\section{Alternative Coding for Primary Outcomes}

As described in the main text, driven by past theory and research on health insurance expansions, ${ }^{3}$ we re-coded the self-rated overall health status for parents and children.

Specifically, overall health status was reported on a continuous 5-point scale $(1=$ Excellent, $2=$ Very Good, $3=$ Good, $4=$ Fair, and $5=$ Poor) for both parents and children in the ECLSK:2011 data. Similarly, we use the composite child BMI values provided in the data for our main results. However, children's BMI is often converted to percentiles or standardized scores (Zscores) based on age- and sex-specific growth charts provided by the CDC in the U.S. In Table S6, we present comparable DD results on the continuous, 5-point measure of health status (for both parents and children), BMI Z-scores, and BMI Z-score-based overweight, obese, and underweight indicators for completeness.

\footnotetext{
${ }^{1}$ Dropping this sample of children/parents who were likely eligible for Medicaid expansions prior to the ACA is a more conservative approach because past research shows "welcome mat" effects for that sample (Hudson \& Moriya, 2017). Nevertheless, this alternative model specification teases the causal effects on the most appropriate "targeted" population of the ACA expansions.
} 
First, the parental health effects are fairly robust. Post-ACA expansion, parents are less likely to report worse health. Child health results are also similar —again, we do not observe any significant changes in this measure. Results on BMI-Z Scores and BMI-Z Score-based overweight indicator are also not statistically significant. Because BMI Z-Scores are calculated using age- and sex-specific CDC growth charts based on cross-sectional data, they are not wellsuited ${ }^{4,5}$ for use in longitudinal models, such as those in the present study that tease out fairly small, within-child changes across states in BMI trajectories post-ACA.

\section{Alternative Sample Selection and Fixed Effects Specification}

Second, we also explored if our baseline results are robust to alternative sample selections (such as households with less than 100\% FPL, households where parents do not have a college-degree) or the exclusion of individual fixed effects (see Table S7). We find that the results are qualitatively similar to our baseline results.

\section{Staggered Treatment Timing}

Finally, we briefly examine if the staggered timing of the Medicaid expansions across states affects the robustness of our baseline results. In our analytical sample, we have three different expansion timings - most states (20) expanded in January 2014 or earlier, 1 state (Michigan) expanded late in April 2014 (coded as expanded in 2014 onwards in our baseline analysis), 3 states (Indiana, New Hampshire, and Pennsylvania) expanded in 2015, and 1 state (Montana) expanding in 2016 (see Table S1). First, following past ACA literature, ${ }^{6}$ we re-run our DD analysis by excluding the late expanders and report results in Table S8. The coefficients are qualitatively similar to the baseline results despite lower precision for parent health.

Second, we also carried out the Goodman-Bacon decomposition ${ }^{7}$ for the main outcomes of interest for which we report significant results—child BMI and parent health. Again, similar 
to earlier studies, ${ }^{6}$ we do not expect earlier treatment cohorts to influence heavily in comparisons (by acting as controls) to later treatment cohorts due to a low number of late treatment states in our analytical sample. Also, because we have a large sample of "never treated" cohorts, we do not expect this to be issue. Nevertheless, following past ACA literature on this topic, ${ }^{6}$ we include the results from the Goodman-Bacon decomposition that essentially examines all 2x2 DD analysis independently. ${ }^{7}$ Specifically, the decomposition provides weights and coefficients to isolate the effect from treatment timing variation ("Earlier Group Treatment" vs. "Later Group Control" and "Later Group Treatment" vs. "Earlier Group Control") and from comparisons of "Treatment" vs. "Never Treated" (see Figure S2). We find that 92 percent of our DD estimate of parent health and 93.5 percent of our DD estimate on child BMI comes from comparisons of treated and never treated (i.e., weight attributed to closed triangles in the figure). In other words, only 7-8 percent is attributable to comparisons with states with differential treatment timing (summing weights across the x's). Together, these additional robustness checks increases our confidence that staggered treatment timing does not play a strong role in our analysis. 


\section{Supplemental References}

1. Juvonen J, Lessard LM, Schacter HL, Suchilt L. Emotional Implications of Weight Stigma across Middle School: The Role of Weight-Based Peer Discrimination. J Clin Child Adolesc Psychol. 2017;46(1):150-158. doi:10.1080/15374416.2016.1188703

2. Mustillo SA, Budd K, Hendrix K. Obesity, Labeling, and Psychological Distress in LateChildhood and Adolescent Black and White Girls: The Distal Effects of Stigma. Soc Psychol Q. 2013;76(3):268-289. doi:10.1177/0190272513495883

3. Thompson O. The long-term health impacts of Medicaid and CHIP. Journal of Health Economics. 2017;51:26-40. doi:10.1016/j.jhealeco.2016.12.003

4. Berkey CS, Colditz GA. Adiposity in Adolescents: Change in Actual BMI Works Better Than Change in BMI z Score for Longitudinal Studies. Annals of Epidemiology. 2007;17(1):44-50. doi:10.1016/j.annepidem.2006.07.014

5. Cole TJ, Faith MS, Pietrobelli A, Heo M. What is the best measure of adiposity change in growing children: BMI, BMI \%, BMI z -score or BMI centile? European Journal of Clinical Nutrition. 2005;59(3):419-425. doi:10.1038/sj.ejcn.1602090

6. Miller S, Johnson N, Wherry LR. Medicaid and Mortality: New Evidence From Linked Survey and Administrative Data*. The Quarterly Journal of Economics. 2021;136(3):17831829. doi:10.1093/qje/qjab004

7. Goodman-Bacon A. Difference-in-differences with variation in treatment timing. Journal of Econometrics. Published online June 12, 2021. doi:10.1016/j.jeconom.2021.03.014

8. Goodman-Bacon A, Goldring T, Nichols A. BACONDECOMP: Stata Module to Perform a Bacon Decomposition of Difference-in-Differences Estimation. Boston College Department of Economics; 2019. Accessed October 5, 2021. https://ideas.repec.org/c/boc/bocode/s458676.html 


\section{Tables and Graphs}

Table S1. Timing of ACA Medicaid Expansion States

\begin{tabular}{|c|c|c|c|c|c|}
\hline & $\begin{array}{l}\text { Early* } \\
\text { Expansion } \\
\text { States }\end{array}$ & $\begin{array}{l}\text { Expansion } \\
\text { States (January } \\
2014 \text { ) }\end{array}$ & $\begin{array}{l}\text { Late* } \\
\text { Expansion } \\
\text { States }\end{array}$ & $\begin{array}{l}\text { Non- } \\
\text { Expansion } \\
\text { States }\end{array}$ & $\begin{array}{l}\text { No ECLS-K } \\
\text { Data } \pm\end{array}$ \\
\hline 1 & California & Arizona & Indiana & Alabama & Alaska \\
\hline 2 & Connecticut & Arkansas & Michigan & Florida & Delaware \\
\hline 3 & Hawaii & Colorado & Montana & Georgia & Idaho \\
\hline 4 & Massachusetts & Illinois & $\begin{array}{l}\text { New } \\
\text { Hampshire }\end{array}$ & Kansas & Kentucky \\
\hline 5 & Minnesota & Iowa & Pennsylvania & Louisiana*** & Maine \\
\hline 6 & New Jersey & Maryland & & Mississippi & North Dakota \\
\hline 7 & New York & Nevada & & Missouri & Rhode Island \\
\hline 8 & Vermont & New Mexico & & Nebraska & South Dakota \\
\hline 9 & Washington & Ohio & & North Carolina & $\begin{array}{l}\text { Washington, } \\
\text { D.C. }\end{array}$ \\
\hline 10 & & Oregon & & Oklahoma & Wyoming \\
\hline 11 & & West Virginia & & South Carolina & \\
\hline 12 & & Wisconsin** & & Tennessee & \\
\hline 13 & & & & Texas & \\
\hline 14 & & & & Utah & \\
\hline 15 & & & & Virginia & \\
\hline
\end{tabular}

* Early expanders are treated as if they expanded in 2014, meaning all time points prior to 2014 (waves 1-4) are coded as not yet expanded for these states as well because the expansions/enrollment to Medicaid was effective beginning in 2014 for these states. Late expanders are treated as expanded only in the years after their expansion.

** Although Wisconsin did not technically expand its Medicaid program under the ACA, it covers adults up to $100 \%$ FPL.

***Louisiana expanded in July 2016, but this timing is beyond the study period. Therefore, we consider it a non-expansion state in this study.

\pm Of these, in our study period, the following would have been considered as (1) non-expansion states: Idaho, Maine, South Dakota, and Wyoming; and (2) expansion states: Alaska (2015), Delaware, Kentucky, North Dakota, Rhode Island, and Washington, D.C. 
Table S2. Linear Pre-trends Test Among Low-Income Households (<138\% FPL)

\begin{tabular}{lcc}
\hline A. Parent Health & Overall Health \\
\hline & $(1)$ \\
\hline Expansion x Wave & -0.012 \\
& $(0.009)$ \\
Observations $^{\text {a }}$ & 6,160 \\
\hline B. Child Health Utilization & Doctor Visits \\
\hline \multicolumn{3}{c}{$(1)$} \\
\hline Expansion x Wave & -0.003 \\
Observations ${ }^{\text {a }}$ & $(0.010)$ \\
\hline C. Child Health & 9,420 & \\
\hline & Overall Health & BMI \\
\hline & $(1)$ & $(2)$ \\
Obsansion x Wave & -0.001 & -0.04 \\
& $(0.003)$ & $(0.042)$ \\
\hline
\end{tabular}

Notes: Sample is restricted to the pre-expansion time period only in this table. Each cell corresponds to a different OLS regression. Expansion $\mathrm{x}$ Wave is an interaction between a binary variable representing whether a child resided in a state that expanded its Medicaid program and a linear wave term. The regressions also include wave, child fixed effects, state-level covariates, and are weighted by sampling weights. Heteroscedasticity-robust standard errors in parentheses, clustered at the state-level.

a Sample size (in child-years) rounded to the nearest 10 as per dataset guidelines;

$* p<0.05, * * p<0.01, * * * p<0.001$. 
Table S3. Heterogenous Effects on Primary Outcomes Among Low-Income Households (< $138 \%$ FPL)

A. Parent Health

B. Child BMI

\begin{tabular}{lcccccc}
\hline A. By Race/Ethnicity & White & Black & Hispanic & White & Black & Hispanic \\
\hline & $(1)$ & $(2)$ & $(3)$ & $(1)$ & $(2)$ & $(3)$ \\
\hline Expansion & 0.042 & $0.080^{*}$ & 0.013 & $-0.447^{*}$ & -0.209 & -0.277 \\
& $(0.022)$ & $(0.033)$ & $(0.031)$ & $(0.191)$ & $(0.312)$ & $(0.192)$ \\
Mean DV & 0.864 & 0.823 & 0.792 & 16.96 & 24.06 & 16.98 \\
Observations ${ }^{\text {a }}$ & 2,880 & 1,390 & 5,290 & 4,330 & 2,310 & 8,310 \\
\hline B. By Sex & Parents & Parents & & Boys & Girls & \\
& of Boys & of Girls & & & & \\
\hline Expansion & $(1)$ & $(2)$ & & $(1)$ & $(2)$ & \\
& $0.047^{* *}$ & 0.022 & & -0.207 & $-0.467^{* *}$ & \\
Mean DV & $(0.014)$ & $(0.021)$ & & $(0.168)$ & $(0.171)$ & \\
Observations ${ }^{\text {a }}$ & 0.815 & 0.844 & & 16.99 & 16.76 & \\
\hline C. By Income & 5,550 & 5,210 & & 8,670 & 8,170 & \\
& Below & Above & & Below & Above & \\
& Median & Median & & Median & Median & \\
& Income & Income & & Income & Income & \\
\hline Expansion & $(1)$ & $(2)$ & & $(1)$ & $(2)$ & \\
& $0.076^{* * *}$ & -0.010 & & $-0.361^{*}$ & -0.244 & \\
Mean DV & $(0.020)$ & $(0.021)$ & & $(0.169)$ & $(0.204)$ & \\
Observations ${ }^{a}$ & 0.790 & 0.868 & & 16.98 & 16.77 & \\
\hline Nos Ean & 5,370 & 5,380 & & 8,450 & 8,340 & \\
\hline
\end{tabular}

Notes: Each column of each panel corresponds to a different OLS regression model. Each model includes wave and child fixed effects and sampling weights. Expansion represents $\beta_{1}$ from equation (1), and measures the average effect of the Medicaid expansions after it took place. Heteroscedasticity-robust standard errors, in parentheses, are clustered at the state level. ${ }^{a}$ Sample sizes (in child-years) are rounded to the nearest 10 as per dataset guidelines.

$* p<0.05, * * p<0.01, * * * p<0.001$. 
Table S4. Heterogenous Effects on Primary Outcomes Among Low-Income Households (< $138 \%$ FPL)

\begin{tabular}{lcccccc}
\hline & \multicolumn{3}{c}{ C. Child Health } & \multicolumn{3}{c}{ D. Child Health Utilization } \\
\hline A. By Race/Ethnicity & White & Black & Hispanic & White & Black & Hispanic \\
\hline & $(1)$ & $(2)$ & $(3)$ & $(1)$ & $(2)$ & $(3)$ \\
\hline Expansion & 0.001 & 0.006 & -0.0138 & 0.022 & -0.035 & 0.031 \\
& $(0.012)$ & $(0.014)$ & $(0.0229)$ & $(0.025)$ & $(0.033)$ & $(0.025)$ \\
Mean DV & 0.974 & 0.930 & 0.919 & 0.940 & 0.956 & 0.919 \\
Observations ${ }^{\text {a }}$ & 4130 & 2,030 & 7,450 & 2,970 & 1,470 & 5,580 \\
\hline B. By Sex & Boys & Girls & & Boys & Girls & \\
\hline & $(1)$ & $(2)$ & & $(1)$ & $(2)$ & \\
\hline Expansion & -0.017 & 0.011 & & -0.012 & 0.036 & \\
& $(0.013)$ & $(0.014)$ & & $(0.022)$ & $(0.026)$ & 0.931 \\
Mean DV & 0.925 & 0.959 & & 0.931 & 0.931 \\
Observations ${ }^{\text {a }}$ & 7,890 & 7,410 & & 5,780 & 5,390 & \\
\hline C. By Income & Below & Above & & Below & Above & \\
& Median & Median & & Median & Median & \\
& Income & Income & & Income & Income & $(2)$ \\
\hline Expansion & $(1)$ & $(2)$ & & $(1)$ & $(2)$ & \\
& -0.017 & 0.006 & & 0.037 & -0.014 & \\
Mean DV & $(0.014)$ & $(0.012)$ & & $(0.022)$ & $(0.028)$ & \\
Observations ${ }^{a}$ & 0.926 & 0.958 & & 0.920 & 0.941 & \\
\hline
\end{tabular}

Notes: Each column of each panel corresponds to a different OLS regression model. Each model includes wave and child fixed effects and sampling weights. Expansion represents $\beta_{1}$ from equation (1), and measures the average effect of the Medicaid expansions after it took place. Heteroscedasticity-robust standard errors, in parentheses, are clustered at the state level. ${ }^{a}$ Sample sizes (in child-years) are rounded to the nearest 10 as per dataset guidelines.

$* p<0.05, * * p<0.01, * * * p<0.001$. 
Table S5. Pre-ACA Parental Income Eligibility Thresholds (as of 2011) for Expansion States included in ECLS-K Data, \% of FPL

\begin{tabular}{lclc}
\hline ARIZONA & 106 & NEW JERSEY & 200 \\
ARKANSAS & 17 & NEW MEXICO & 67 \\
CALIFORNIA & 106 & NEW YORK & 150 \\
COLORADO & 106 & OHIO & 90 \\
CONNECTICUT & 191 & OREGON & 40 \\
HAWAII & 100 & PENNSYLVANIA & 46 \\
ILLINOIS & 191 & VERMONT & 191 \\
INDIANA & 36 & WASHINGTON & 74 \\
IOWA & 83 & WEST VIRGINIA & 33 \\
MARYLAND & 116 & WISCONSIN & 200 \\
MASSACHUSETTS & 133 & & \\
MICHIGAN & 64 & & \\
MINNESOTA & 215 & & \\
MONTANA & 56 & & \\
NEVADA & 88 & & \\
NEW HAMPSHIRE & 49 & &
\end{tabular}

Source: Data come from Kaiser Family Foundation, "Medicaid Income Eligibility Limits for Parents, 2002-2020." https://www.kff.org/medicaid/state-indicator/medicaid-incomeeligibility-limits-for-parents/ 
Table S6. Alternative Outcome Coding Among Low-Income Households ( $<138 \%$ FPL)

\begin{tabular}{|c|c|c|c|c|c|c|}
\hline A. Parent Health & $\begin{array}{c}\text { Overall } \\
\text { Health } \\
\text { (Continuo } \\
\text { us 1-5) }\end{array}$ & $\begin{array}{c}\text { Overall } \\
\text { Health } \\
\text { (Very } \\
\text { Good/Exc } \\
\text { ellent }=1)\end{array}$ & & & & \\
\hline & (1) & (2) & & & & \\
\hline Expansion & $\begin{array}{l}-0.0742 * \\
(0.0344)\end{array}$ & $\begin{array}{c}0.017 \\
(0.018)\end{array}$ & & & & \\
\hline Mean DV & 2.494 & 0.77 & & & & \\
\hline Observations $^{\text {a }}$ & 10,760 & 10,760 & & & & \\
\hline C. Child Health & $\begin{array}{c}\text { Overall } \\
\text { Health } \\
\text { (Continuo } \\
\text { us 1-5) }\end{array}$ & $\begin{array}{c}\text { Overall } \\
\text { Health } \\
\text { (Very } \\
\text { Good/Exc } \\
\text { ellent }=1)\end{array}$ & $\begin{array}{c}\text { BMI Z- } \\
\text { Score } \\
\text { (Using } \\
\text { Age-Sex- } \\
\text { Specific } \\
\text { CDC } \\
\text { Growth } \\
\text { Charts) }\end{array}$ & $\begin{array}{c}\text { BMI Z- } \\
\text { Score } \\
\text { Based } \\
\text { Overweig } \\
\text { ht } \\
\text { Indicator } \\
\text { (Using } \\
\text { Age-Sex- } \\
\text { Specific } \\
\text { CDC } \\
\text { Growth } \\
\text { Charts) } \\
\end{array}$ & $\begin{array}{l}\text { BMI Z- } \\
\text { Score } \\
\text { Based } \\
\text { Obesity } \\
\text { Indicator } \\
\text { (Using } \\
\text { Age-Sex- } \\
\text { Specific } \\
\text { CDC } \\
\text { Growth } \\
\text { Charts) }\end{array}$ & $\begin{array}{l}\text { BMI Z- } \\
\text { Score } \\
\text { Based } \\
\text { Underwei } \\
\text { ght } \\
\text { Indicator } \\
\text { (Using } \\
\text { Age-Sex- } \\
\text { Specific } \\
\text { CDC } \\
\text { Growth } \\
\text { Charts) } \\
\end{array}$ \\
\hline & (1) & (2) & (3) & (4) & (5) & (6) \\
\hline Expansion & $\begin{array}{c}0.050 \\
(0.029)\end{array}$ & $\begin{array}{l}-0.017 \\
(0.016)\end{array}$ & $\begin{array}{c}0.024 \\
(0.034)\end{array}$ & $\begin{array}{c}0.008 \\
(0.018)\end{array}$ & $\begin{array}{l}-0.010 \\
(0.011)\end{array}$ & $\begin{array}{l}-0.012 \\
(0.007)\end{array}$ \\
\hline Mean DV & 1.858 & 0.782 & 0.641 & 0.551 & 0.194 & 0.023 \\
\hline Observations $^{\text {a }}$ & 15,300 & 15,300 & 16,780 & 16,780 & 16,780 & 16,780 \\
\hline
\end{tabular}

Notes: Each column of each panel corresponds to a different OLS regression model. Each model includes wave and child fixed effects and sampling weights. Expansion represents $\beta_{1}$ from equation (1), as shown in appendix, and measures the average effect of the Medicaid expansions after it took place. Mean of each dependent variable (DV) provides the within-child average of the DV after controlling for just wave fixed effects. Heteroscedasticity-robust standard errors, in parentheses, are clustered at the state level. ${ }^{\text {a }}$ Sample sizes (in child-years) are rounded to the nearest 10 as per dataset guidelines. ${ }^{*} p<0.05,{ }^{* *} p<0.01,{ }^{* * *} p<0.001$. 
Table S7. Additional Robustness Checks

\begin{tabular}{|c|c|c|c|c|c|c|}
\hline \multirow[t]{2}{*}{ A. Parent Health } & \multicolumn{3}{|c|}{ Overall Health } & & & \\
\hline & $\begin{array}{c}\text { Less than } \\
100 \% \\
\text { FPL }\end{array}$ & $\begin{array}{l}\text { Parents } \\
\text { with less- } \\
\text { than } \\
\text { college } \\
\text { education }\end{array}$ & $\begin{array}{c}\text { No } \\
\text { Individual } \\
\text { Fixed } \\
\text { Effects } \\
\text { (Less than } \\
138 \% \\
\text { FPL) }\end{array}$ & & & \\
\hline Expansion & $\begin{array}{c}0.030^{*} \\
(0.0113)\end{array}$ & $\begin{array}{l}0.026^{* *} \\
(0.008)\end{array}$ & $\begin{array}{c}0.043 * * * \\
(0.010)\end{array}$ & & & \\
\hline Mean of DV & 0.806 & 0.882 & 0.835 & & & \\
\hline $\begin{array}{l}\text { Time Varying State } \\
\text { Covariates }\end{array}$ & No & No & No & & & \\
\hline Observations ${ }^{a}$ & 7,860 & 20,770 & 10,760 & & & \\
\hline R-squared (within-child) & 0.006 & 0.003 & 0.024 & & & \\
\hline \multirow[t]{2}{*}{ B. Child Health Utilization } & \multicolumn{3}{|c|}{ Doctor Visits } & & & \\
\hline & $\begin{array}{c}\text { Less than } \\
100 \% \\
\text { FPL }\end{array}$ & $\begin{array}{c}\text { Parents } \\
\text { with less- } \\
\text { than } \\
\text { college } \\
\text { education }\end{array}$ & $\begin{array}{c}\text { No } \\
\text { Individual } \\
\text { Fixed } \\
\text { Effects } \\
\text { (Less } \\
\text { than } \\
138 \% \\
\text { FPL) } \\
\end{array}$ & & & \\
\hline Expansion & $\begin{array}{l}0.013 \\
(0.014)\end{array}$ & $\begin{array}{l}0.003 \\
(0.012)\end{array}$ & $\begin{array}{l}-0.002 \\
(0.013)\end{array}$ & & & \\
\hline Mean of DV & 0.93 & 0.92 & 0.934 & & & \\
\hline $\begin{array}{l}\text { Time Varying State } \\
\text { Covariates }\end{array}$ & No & No & No & & & \\
\hline Observations $^{a}$ & 8,190 & 21,670 & 11,160 & & & \\
\hline R-squared (within-child) & 0.010 & 0.010 & 0.035 & & & \\
\hline \multirow[t]{2}{*}{ C. Child Health } & \multicolumn{3}{|c|}{ Overall Health } & \multicolumn{3}{|c|}{ Child BMI } \\
\hline & $\begin{array}{c}\text { Less than } \\
100 \% \\
\text { FPL }\end{array}$ & $\begin{array}{c}\text { Parents } \\
\text { with less- } \\
\text { than } \\
\text { college } \\
\text { education }\end{array}$ & $\begin{array}{c}\text { No } \\
\text { Individual } \\
\text { Fixed } \\
\text { Effects } \\
\text { (Less than } \\
138 \% \\
\text { FPL) }\end{array}$ & $\begin{array}{l}\text { Less than } \\
100 \% \text { FPL }\end{array}$ & $\begin{array}{l}\text { Parents } \\
\text { with less- } \\
\text { than } \\
\text { college } \\
\text { education }\end{array}$ & $\begin{array}{c}\text { No } \\
\text { Individual } \\
\text { Fixed } \\
\text { Effects } \\
\text { (Less than } \\
138 \% \\
\text { FPL) }\end{array}$ \\
\hline Expansion & $\begin{array}{l}-0.014 \\
(0.008)\end{array}$ & $\begin{array}{l}-0.003 \\
(0.004)\end{array}$ & $\begin{array}{l}-0.003 \\
(0.009)\end{array}$ & $\begin{array}{c}-0.501 * * * \\
(0.140)\end{array}$ & $\begin{array}{c}-0.341^{* *} \\
(0.113)\end{array}$ & $\begin{array}{c}-0.443^{* *} \\
(0.131)\end{array}$ \\
\hline Mean of DV & 0.93 & 0.96 & 0.875 & 16.94 & 16.76 & 16.23 \\
\hline $\begin{array}{l}\text { Time Varying State } \\
\text { Covariates }\end{array}$ & No & No & No & No & No & No \\
\hline Observations $^{\text {a }}$ & 11,210 & 29,780 & 15,300 & 12,410 & 31,940 & 16,840 \\
\hline R-squared (within-child) & 0.003 & 0.001 & 0.010 & 0.465 & 0.475 & 0.160 \\
\hline
\end{tabular}

Notes: Each column of each panel corresponds to a different OLS regression model. Each model includes wave and child fixed effects and sampling weights. Expansion represents $\beta$ from equation (2), as shown in appendix, and measures the average effect of the Medicaid expansions after it took place. Mean of each dependent variable (DV) 
provides the within-child average of the DV after controlling for just wave fixed effects. Heteroscedasticity-robust standard errors, in parentheses, are clustered at the state level. a Sample sizes (in child-years) are rounded to the nearest 10 as per dataset guidelines. $* \mathrm{p}<0.05,{ }^{* *} \mathrm{p}<0.01,{ }^{* * *} \mathrm{p}<0.001$. 
Table S8. Impact of the ACA Medicaid Expansion on Health Outcomes Excluding Late Expansion States

\begin{tabular}{|c|c|c|}
\hline A. Parent Health & $\begin{array}{l}\text { Overall } \\
\text { Health }\end{array}$ & \\
\hline & (1) & \\
\hline Expansion & 0.020 & \\
\hline & $(0.018)$ & \\
\hline Mean of DV & 0.72 & \\
\hline Time Varying State Covariates & Yes & \\
\hline Observations $^{\text {a }}$ & 7,706 & \\
\hline R-squared (within-child) & 0.005 & \\
\hline B. Child Health Utilization & $\begin{array}{c}\text { Doctor } \\
\text { Visits }\end{array}$ & \\
\hline & (1) & \\
\hline Expansion & $\begin{array}{c}0.002 \\
(0.019)\end{array}$ & \\
\hline Mean of DV & 0.92 & \\
\hline Time Varying State Covariates & Yes & \\
\hline Observations ${ }^{\text {a }}$ & 8,000 & \\
\hline R-squared (within-child) & 0.013 & \\
\hline C. Child Health & $\begin{array}{l}\text { Overall } \\
\text { Health }\end{array}$ & BMI \\
\hline & (1) & (2) \\
\hline Expansion & $\begin{array}{l}0.0002 \\
(0.011)\end{array}$ & $\begin{array}{l}-0.337^{*} \\
(0.146)\end{array}$ \\
\hline Mean of DV & 0.81 & 0.47 \\
\hline Time Varying State Covariates & Yes & Yes \\
\hline Observations $^{\text {a }}$ & 11,370 & 15,600 \\
\hline R-squared (within-child) & 0.013 & 0.002 \\
\hline
\end{tabular}

Notes: Each column of each panel corresponds to a different OLS regression model. Each model includes wave and child fixed effects, state-level covariates, and sampling weights. Expansion represents $\beta_{1}$ from equation (1) as shown in appendix, estimated for sub-sample of lower-income $(<138 \%$ FPL $)$ households after the exclusion of the late expansion states. As before, the coefficient measures the average effect of the Medicaid expansions after it took place. Mean of each dependent variable (DV) provides the within-child average of the DV after controlling for just wave fixed effects. Heteroscedasticity-robust standard errors, in parentheses, are clustered at the state level.

${ }^{a}$ Sample sizes (in child-years) are rounded to the nearest 10 as per dataset guidelines.

$* p<0.05, * * p<0.01, * * * p<0.001$. 


\section{Figure S1. Event-Study Graphs}

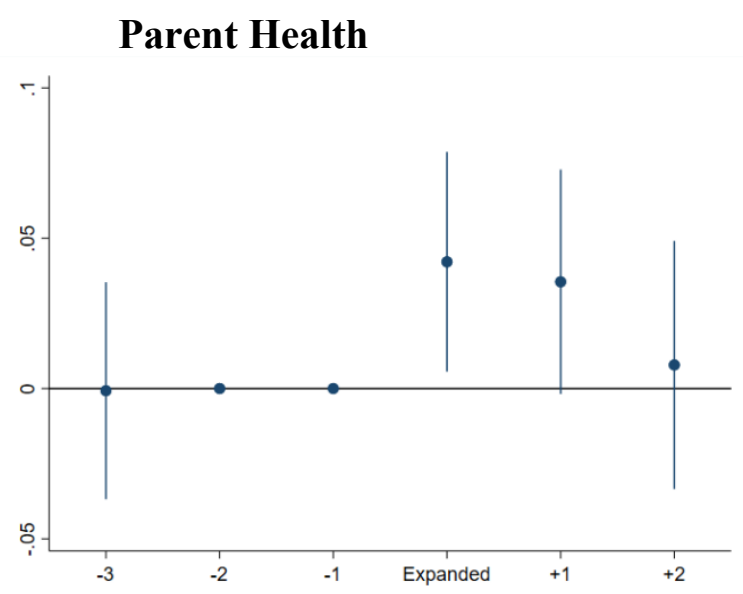

Child Health Utilization

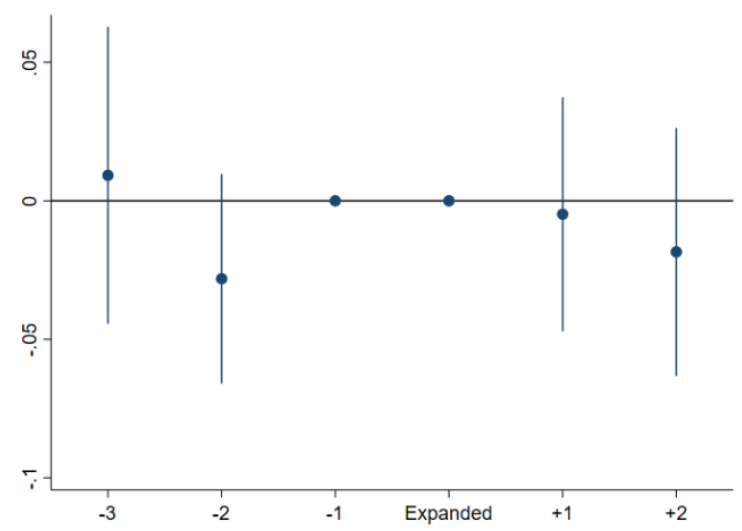

Child Health (Overall Health)

Child Health (BMI)
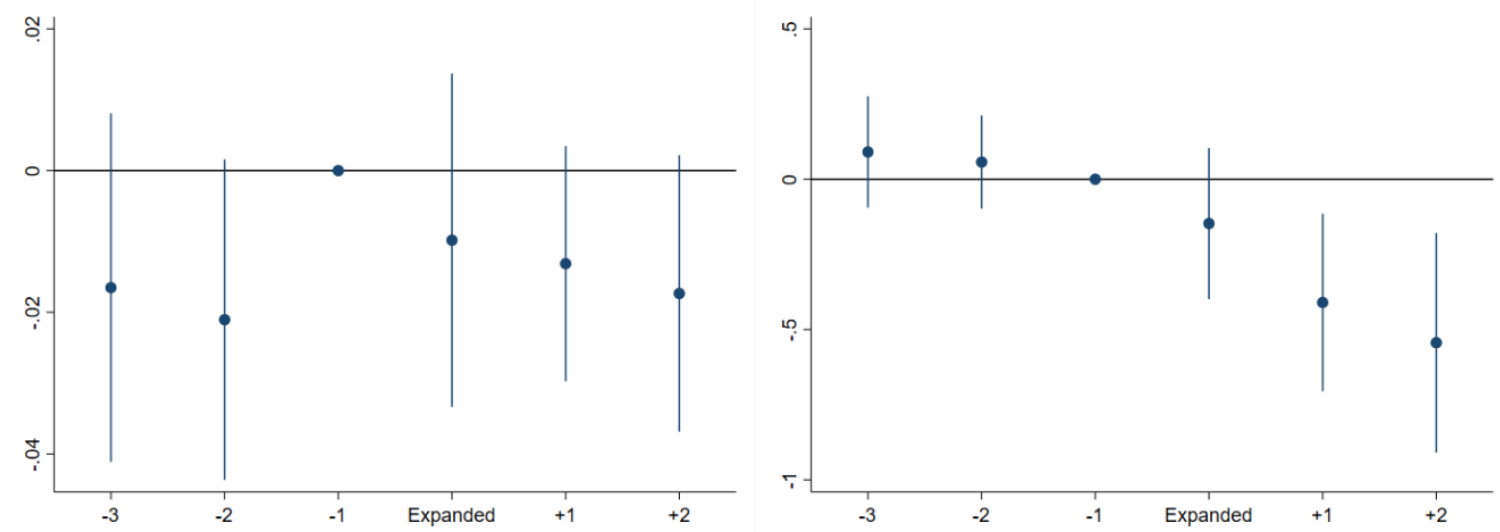

Notes: Each bar represents the 95 percent confidence internal (constructed with standard errors clustered at the state level), and the center of the bar represents the point estimate. The coefficient for the group "-1" (i.e. the one year prior to the Medicaid expansion) is normalized to zero. Similarly, coefficients for years in which the outcome is not measured in the sample is also reported as zero. Sample is limited to children in households with incomes below 138\% FPL. 
Figure S2. Goodman-Bacon Decomposition

\section{Parent Health}

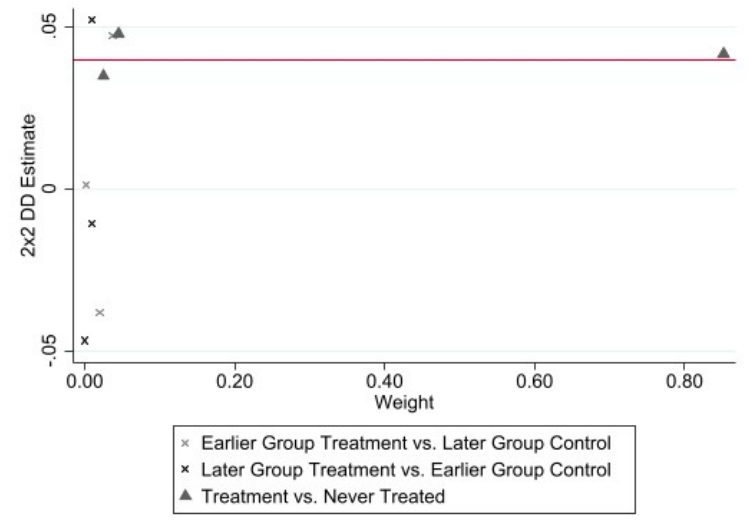

Child Health (BMI)

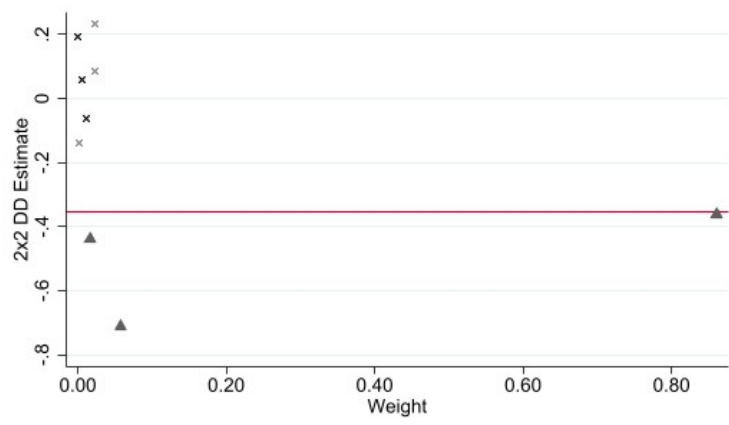

× Earlier Group Treatment vs. Later Group Control $\times$ Later Group Treatment vs. Earlier Group Control

$\Delta$ Treatment vs. Never Treated

Notes: Figure displays estimates and weights from the Goodman-Bacon decomposition ${ }^{7}$ implemented with the aid of the user-written Stata command "bacondecomp". 8 Red horizontal line shows the combined DD estimate, and x's and triangles represent the various of $2 \times 2$ DD estimates scattered with weights for each of those comparisons shown on the X-axis. Because the decomposition implementation in STATA does not allow sampling weights or time-varying covariates, the combined DD estimates $(0.04$ for parent health and -0.35 for child BMI shown in the figure) are slightly different from our preferred specification in Table 2 . Also, we imputed the median values for parent health when values were missing and for both parent health and child BMI we create fully balanced panels to allow decomposition to execute the full comparisons. Finally, summing the weights on the timing terms (x's) show that only 8 (7) percent of the DD estimate on parent health (child BMI) comes from timing variation. 